\title{
Bioactivity and Plant Growth Stimulation Studies using Mangifera indica L. Gum
}

\author{
Antony V. Samrot ${ }^{1 *}(\mathbb{D})$, Lee Si Jie ${ }^{1}$, S. Abirami ${ }^{2}$, R. Emilin Renitta ${ }^{3}$, \\ S. Dhiva ${ }^{4}$, P. Prakash ${ }^{5}$, S. Saigeetha ${ }^{6}$ and N. Shobana ${ }^{5}$ \\ ${ }^{1}$ School of Bioscience, Faculty of Medicine, Bioscience and Nursing, MAHSA University, Jenjarom, Selangor \\ 42610, Malaysia. \\ ${ }^{2}$ Department of Microbiology, Kamaraj College, Thoothukudi - 628 003, Tamil Nadu, India. \\ ${ }^{3}$ Department of Food Processing Technology, School of Agriculture and Biosciences, Karunya Institute of \\ Science and Technology, Karunya Nagar, Coimbatore - 641 114, Tamil Nadu, India. \\ ${ }^{4}$ Department of Microbiology, Sree Narayana College, Alathur, Palakkad, Kerala - 678 682, Kerala, India. \\ ${ }^{5}$ Department of Biotechnology, School of Bio and Chemical Engineering, Sathyabama Institute of Science and \\ Technology, Chennai - 600 119, Tamil Nadu, India. \\ ${ }^{6}$ Department of Biotechnology, School of Biosciences and Technology, Vellore Institute of Technology, \\ Vellore, Tamil Nadu- 632014, India.
}

\begin{abstract}
The potential of plant gum as a bioactive agent and plant growth enhancer has not been exploited well and plant gums are suitable for such purposes as they are non-toxic and biodegradable. Therefore, the aim of this study was to verify the potential of Mangifera indica (MI) gum as a bioactive agent and plant growth enhancer. Plant gum was collected from the bark of $\mathrm{MI}$ and polysaccharides were extracted, purified and characterized with ultraviolet-visible (UV-Vis) spectroscopic, Fourier-transform infrared spectroscopy and gas chromatography (GC) analyses. Crude and purified polysaccharides were tested for their antibacterial and antioxidant activity. The crude gum was subjected to plant growth stimulation study like germination percentage, shoot length, root length and wet weight of chilli (Capsicum frutescens). The effect of MI gum on soil porosity and water holding capacity (WHC) was also tested. UV-Vis and GC analyses of gum polysaccharide showed the presence of several types of monosaccharides in MI gum. The plant gum did not show any antibacterial activity against Escherichia coli, Pseudomonas sp., Bacillus sp. and Staphylococcus aureus, but was found to exhibit low antioxidant activity. The gum was found to enhance the seed germination and seedling growth in-vitro and in-vivo.
\end{abstract}

Keywords: Mangifera indica L, Gum, Bioactivity, plant growth

*Correspondence: antonysamrot@gmail.com

(Received: June 19, 2021; accepted: September 01, 2021)

Citation: Samrot AV, Jie LS, Abirami S, et al. Bioactivity and Plant Growth Stimulation Studies using Mangifera indica L. Gum. J Pure Appl Microbiol. 2021;15(4):2073-2084. doi: 10.22207/JPAM.15.4.30

(C) The Author(s) 2021. Open Access. This article is distributed under the terms of the Creative Commons Attribution 4.0 International License which permits unrestricted use, sharing, distribution, and reproduction in any medium, provided you give appropriate credit to the original author(s) and the source, provide a link to the Creative Commons license, and indicate if changes were made. 


\section{INTRODUCTION}

Gums are biomaterials composed of polysaccharides produced naturally either by plants, marine organisms or microorganisms. ${ }^{1}$ Gums of plant origin can be found in seed or branches and bark of woody plants ${ }^{2}$ and are produced in response to injury or environmental stress. ${ }^{2}$ Among all the gum-producing woody plants, higher production of gum was seen in trees of families Fabaceae, Combretaceae and Sterculiaceae, as they produce good quality gum suitable for commercial use. ${ }^{3}$ These gum derived polysaccharides are with excellent biocompatibility, biodegradability and nontoxic, they are suitable to be applied onto living organisms including plants. ${ }^{4}$ Their role as a plant growth enhancer is supported by existing literatures ${ }^{5-7}$ Polysaccharides when added to soil, it is depolymerized by soil microorganisms and converted into essential nutrients readily absorbed by plants. ${ }^{8}$ Mango (Mangifera indica, MI) gum was chosen for our study because mango trees are found abundantly in Malaysia. They can be found growing wild or on roadsides and even growing at home. ${ }^{9} \mathrm{Ml}$ gum was found to contain nutrients required in plant growth such as nitrogen, phosphorus, potassium, calcium and iron..$^{10}$ In this study, Ml gum was tested for its antioxidant and antibacterial activity, and also checked for its phytostimulation study in-vitro and in-vivo.

\section{MATERIALS AND METHODS \\ Materials, Chemicals and Reagents}

F1 hybrid new green eagle chilli seeds (Capsicum frutescens) (Sin Seng Huat
Seeds), Absolute ethanol (Systerm Chemicals), Trichloroacetic acid (Merck Chemicals), Acetone (SRL Chemicals), Nutrient broth (Himedia Chemicals), Nutrient agar (SRL Chemicals), Ascorbic acid (SRL Chemicals), DPPH reagent (SRL Chemicals), Glucose (Sigma-Aldrich) were used in this study. All the reagents used in this study are analytical grade.

\section{Apparatus and Instruments}

Weighing balance (A\&D Company Ltd), Magnetic stirrer (Lab Tech), Centrifuge (Thermo Scientific), Dialysis tubes (Hi Media), UV-Vis Spectrophotometer (Geneva IOS UV-Vis-Thermo Scientific), FTIR (Perkin Elmer Spectrum Two), Biological Safety Cabinet (ESCO Class II BSC), Refrigerator (Thermo Fisher Scientific), Incubator (Thermo Scientific), Hot air oven were used in this study.

\section{Collection of Plant Gum}

Plant gum was collected from the bark of Mangifera indica tree found at Jalan Dato Abdul Hamid 3, Taman Sentosa, Klang, Malaysia after incisions were made (Fig. 1). The collected gum was then transferred to a clean glass container and dried at room temperature.

\section{Extraction and Purification of Polysaccharide}

Crude polysaccharide extract was prepared by dissolving $0.5 \mathrm{~g}$ of gum in $50 \mathrm{ml}$ of distilled water under heat and then filtered. Purification of polysaccharide started with defatting procedure by soaking the gum $(20 \mathrm{~g})$ in $50 \mathrm{ml}$ absolute ethanol and left overnight at room temperature. The sediment was collected and dried in a hot air oven $\left(58^{\circ} \mathrm{C}\right) .10 \mathrm{~g}$ of defatted gum was measured and dissolved in $100 \mathrm{ml}$ of
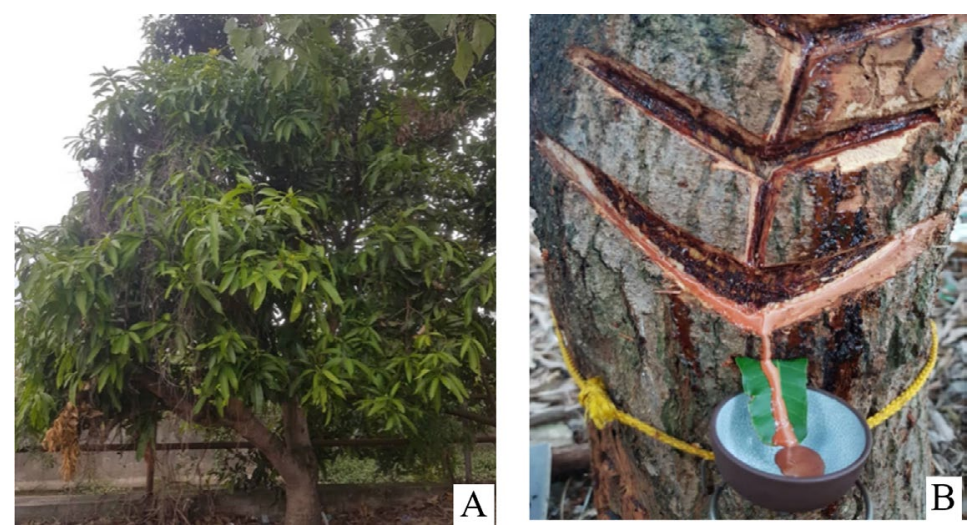

Fig. 1. Collection of plant gum from Mangifera indica tree; A- Plant, B- Gum collected in a silica cup. 
distilled water under continuous stirring for $4 \mathrm{~h}$ using a magnetic stirrer. The solution was filtered using muslin cloth to remove particles that do not dissolve in water. Then, $100 \mathrm{ml}$ of distilled water was added to the filtrate, and stirred under $100{ }^{\circ} \mathrm{C}$ for $1 \mathrm{~h}$. Once solution was cooled to room temperature, it was again filtered. To the filtrate, equal volume of $10 \%$ trichloroacetic acid was added to precipitate out proteins. The solution was then centrifuged at $10,000 \mathrm{rpm}$ for 10 minutes. Supernatant was transferred into a beaker, and acetone was added in 1 to 0.5 ratio (supernatant: acetone). The solution was centrifuged at 10,000 $\mathrm{rpm}$ for $10 \mathrm{~min}$. Supernatant was transferred to dialysis tubes and dialyzed against distilled water for 5 days. Purified polysaccharide was obtained after 5 days of dialysis process. ${ }^{11}$

\section{Characterization of Polysaccharide}

Crude and purified polysaccharide was subjected to UV-Vis spectroscopic analysis. Absorbance was measured at wavelength range from $200 \mathrm{~nm}$ to $800 \mathrm{~nm}$. Purified polysaccharide alone was subjected to FTIR and GC analyses as described earlier. ${ }^{11}$

\section{Bioactivities of Polysaccharide Antibacterial Activity}

Antibacterial activity of polysaccharide was determined using agar well diffusion method. ${ }^{12,13}$ For both crude and purified polysaccharide, they were tested against two Gram positive bacteria (Staphylococcus aureus and Bacillus sp.) and two Gram negative bacteria (Pseudomonas sp. and Escherichia coli). It started by punching holes using a cork borer on the

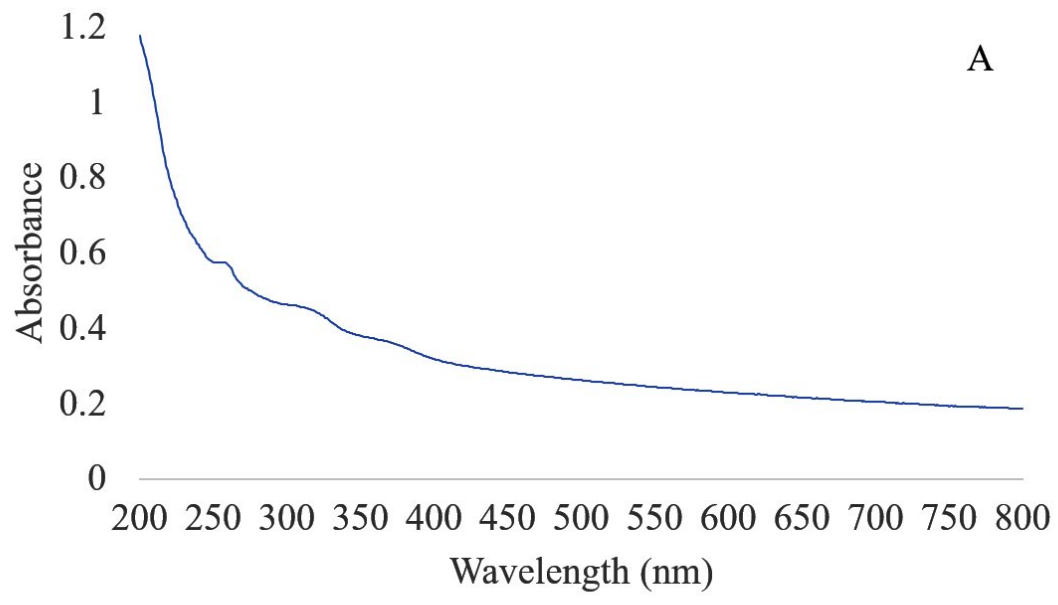

$$
1.2
$$

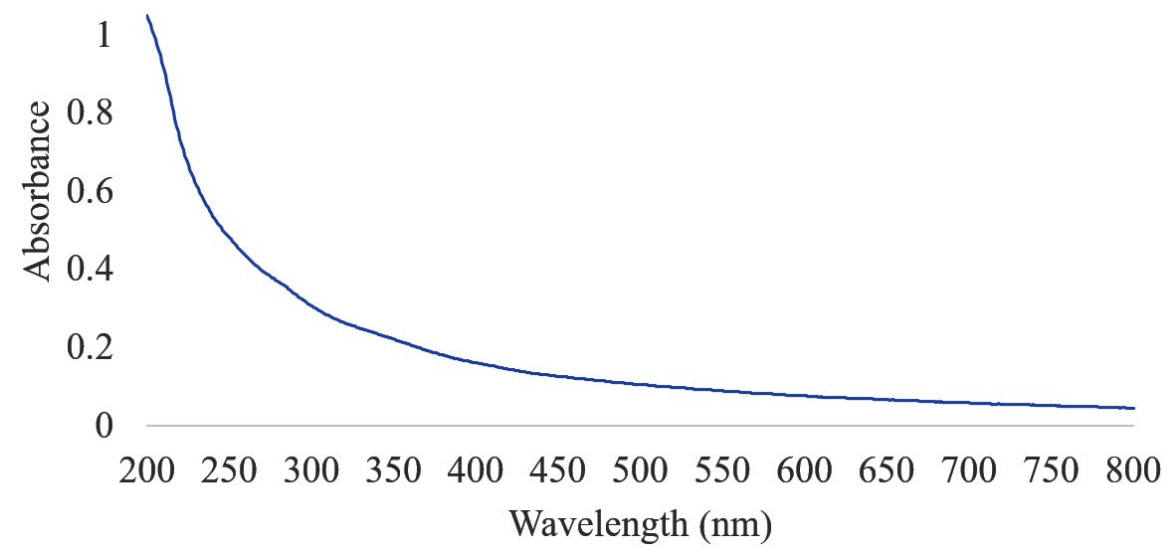

Fig. 2. Results of UV-Vis analysis a) Crude Polysaccharide, b) Purified Polysaccharide. 
nutrient agar, followed by the swabbing of 24 $h$ broth culture over the entire agar. Then, four different concentrations (100 $\mu \mathrm{g}, 200 \mu \mathrm{g}, 300 \mu \mathrm{g}$ and $400 \mu \mathrm{g}$ ) of crude / purified polysaccharide were added into the wells. One well was loaded with distilled water as negative control, and 5 $\mu \mathrm{g}$ ciprofloxacin antibiotic disc was used as the positive control. The agar plates were incubated at $37^{\circ} \mathrm{C}$ overnight. Zone of inhibition was measured 24 hours later.

\section{Swarming Motility Assay}

Nutrient agar plates were prepared with its base layer composed of $1.5 \%$ agar. An overlay was prepared by adding $500 \mu \mathrm{l}$ polysaccharides solution (crude or purified) and $1 \mathrm{ml}$ of $1 \%$ glucose to $20 \mathrm{ml}$ of warmed $0.5 \%$ nutrient agar. The mixture was mixed well and poured on the pre-cooled nutrient agar plates. Agar was allowed to solidify, forming a substrate layer for motile microorganisms. The crude and purified polysaccharides were tested for its ability to inhibit swarming motility of Bacillus sp. and
Escherichia coli. Similar procedure was followed in preparing control plates, with $0.5 \%$ nutrient agar (supplemented with glucose) as substrate layer but without addition of polysaccharides. $10 \mu \mathrm{l}$ of 24 hours bacterial culture was spot inoculated at the centre of substrate layer. Agar plates were then incubated at $37^{\circ} \mathrm{C}$ for $24 \mathrm{~h}$. After incubation, radius ( $r$ ) of biofilm was measured from the spot of inoculation and results were reported in diameter $(d=2 r) .{ }^{14}$

\section{Antioxidant Activity}

Antioxidant activity of polysaccharide was determined using DPPH assay ${ }^{15} .0 .1 \mathrm{mM}$ of DPPH reagent was prepared along with the preparation of various concentrations of crude and purified polysaccharide $(100 \mu \mathrm{g} / \mathrm{ml}, 200 \mu \mathrm{g} /$ $\mathrm{ml}, 300 \mu \mathrm{g} / \mathrm{ml}, 400 \mu \mathrm{g} / \mathrm{ml}$ and $500 \mu \mathrm{g} / \mathrm{ml}$ ). In a test tube, $1 \mathrm{ml}$ of polysaccharide solution was added to $2 \mathrm{ml}$ of DPPH solution and was shaken vigorously. The tubes were allowed to stand at room temperature in dark for a duration of $30 \mathrm{~min}$. After that, absorbance was measured at $517 \mathrm{~nm}$

Table 1. Antibacterial activity of polysaccharide

\begin{tabular}{|c|c|c|c|c|c|c|c|c|c|c|c|c|}
\hline \multirow[t]{4}{*}{ Organism } & \multicolumn{12}{|c|}{ Zone of Inhibition (mm) } \\
\hline & \multicolumn{6}{|c|}{ Crude Polysaccharide } & \multicolumn{6}{|c|}{ Purified Polysaccharide } \\
\hline & \multirow[t]{2}{*}{$P C$} & \multirow[t]{2}{*}{ NC } & \multicolumn{4}{|c|}{ Concentration $(\mu \mathrm{g})$} & \multirow[t]{2}{*}{$\overline{P C}$} & \multirow[t]{2}{*}{ NC } & \multicolumn{4}{|c|}{ Concentration $(\mu \mathrm{g})$} \\
\hline & & & 100 & 200 & 300 & 400 & & & 100 & 200 & 300 & 400 \\
\hline Escherichia coli & 24 & - & - & - & - & - & 23 & - & - & - & - & - \\
\hline Pseudomonas sp. & 33 & - & - & - & - & - & 23 & - & - & - & - & - \\
\hline Staphylococcus aureus & 27 & - & - & - & - & - & 33 & - & - & - & - & - \\
\hline Bacillus sp. & 24 & - & - & - & - & - & 25 & - & - & - & - & - \\
\hline
\end{tabular}

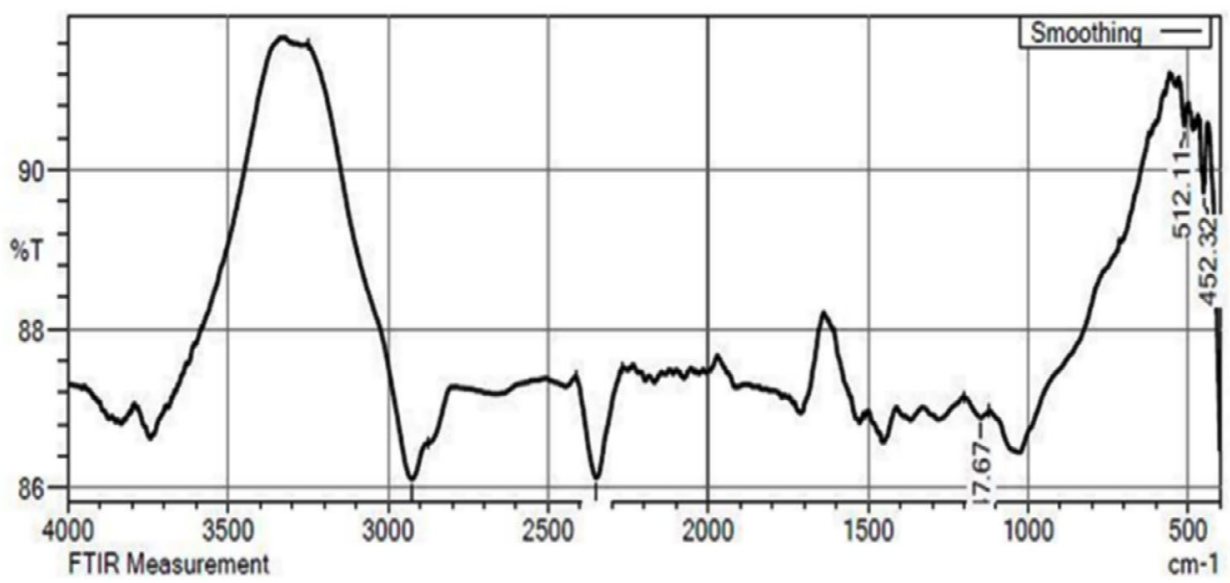

Fig. 3. FTIR spectrum of purified polysaccharide. 
using UV-Vis spectrophotometer. The standard solution used in this assay was ascorbic acid, and it was prepared in different concentrations same as

Table 2. Results of swarming motility assay

\begin{tabular}{lccc}
\hline \multirow{2}{*}{ Organism } & \multicolumn{3}{c}{ Diameter of Biofilm (mm) } \\
\cline { 2 - 4 } & Control & Crude & Purified \\
\hline Bacillus sp. & 10 & 10 & 6 \\
Escherichia coli & 12 & 12 & 6 \\
\hline
\end{tabular}

the test samples. Methanol was used as blank and control was prepared by adding $1 \mathrm{ml}$ of methanol to $2 \mathrm{ml}$ of DPPH solution. DPPH scavenging activity was calculated using the following formula:

$$
\begin{array}{lc}
\text { Absorbance of control - } \\
\begin{array}{l}
\text { DPPH scavenging } \\
\text { activity }(\%)=
\end{array}
\end{array}
$$

Seed Germination and Seedling Growth Study

Total of six plastic round dishes were prepared. 3 control dishes labelled as $\mathrm{C} 1, \mathrm{C} 2$ and

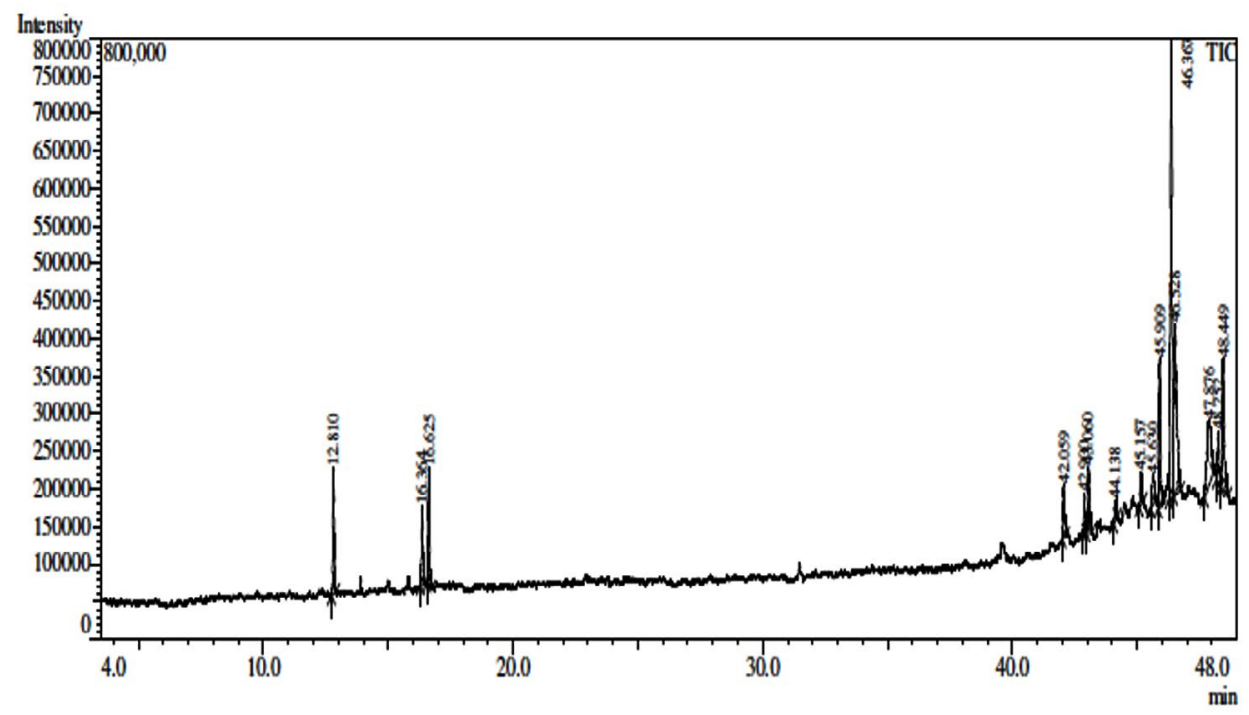

Fig. 4. GC chromatogram of purified polysaccharide.

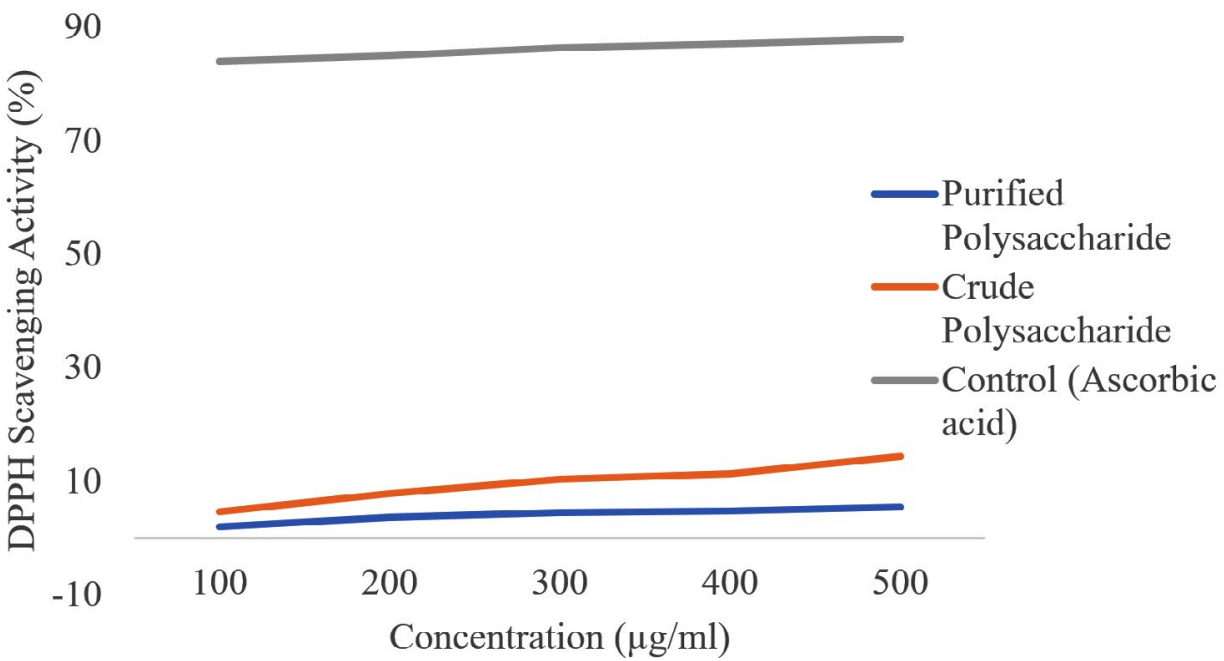

Fig. 5. A comparison of DPPH scavenging activity between purified polysaccharide, crude polysaccharide and ascorbic acid. 
$\mathrm{C} 3$, another 3 were test dishes labelled as $\mathrm{T} 1, \mathrm{~T} 2$ and T3. A layer of cotton was laid on the dish and moisten with distilled water. 5 chilli seeds were placed into each dish. Each seed from the control group received 10 drops of distilled water once per day, and seeds from the test group received 10 drops of $10 \%$ gum solution for three days, followed by distilled water for the remaining days. All dishes were kept in a humid chamber and placed in dark. Number of seeds germinated was recorded every day. With these data, germination percentage was calculated using formula below ${ }^{16}$ :

Germination percentage $=\frac{\text { No. of germinated seeds }}{\text { Total No. of seeds }} \times 100 \%$

Measurement on root length, shoot length and wet weight were done on $18^{\text {th }}, 21^{\text {st }}$ and $24^{\text {th }}$ day.

\section{Effects of Plant Gum on Soil Quality}

Unfertile soil collected was used as negative control, and organic soil was used as positive control. Collected unfertile soil was added

Table 3. Soil porosity of the three different types of soil: positive control, negative control and test

\begin{tabular}{lcc}
\hline $\begin{array}{l}\text { Types of } \\
\text { Soil }\end{array}$ & $\begin{array}{c}\text { Soil Porosity } \\
(\%)\end{array}$ & $\begin{array}{c}\text { WHC } \\
(\%)\end{array}$ \\
\hline Positive Control & 47.5 & 98 \\
Negative Control & 22.0 & 32 \\
Test (Gum-Treated Soil) & 27.0 & 70 \\
\hline
\end{tabular}

with $10 \%$ gum solution and called as test soil. The soil was first spread over a tray. To allow better mixing, gum solution was poured uniformly over the soil followed by thorough mixing. The soil was left undisturbed for two days. The three types of soil were subjected to soil porosity testing and water holding capacity (WHC) determination.

\section{Soil Porosity}

A $250 \mathrm{ml}$ beaker was filled with soil until it reached the $200 \mathrm{ml}$ mark. Then, $100 \mathrm{ml}$ of water in a beaker was slowly poured until water just starts to pool up on the soil surface. The volume left in the beaker was recorded and used in the calculation for volume of water poured. Soil porosity was measured using formula:

Soil Porosity $=\frac{\text { (Volume of water poured) }}{\text { (Volume of soil) }} \times 100 \%$

\section{Water Holding Capacity (WHC)}

$10 \mathrm{~g}$ of soil was measured and transferred into a funnel with filter paper at its base. Then, $100 \mathrm{ml}$ of distilled water was poured onto the soil. The water drained by gravity was collected in a measuring cylinder. WHC in percentage was calculated using formula below ${ }^{17}$ :

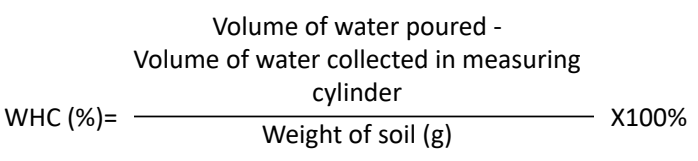
cylinder $\quad$ X100\%

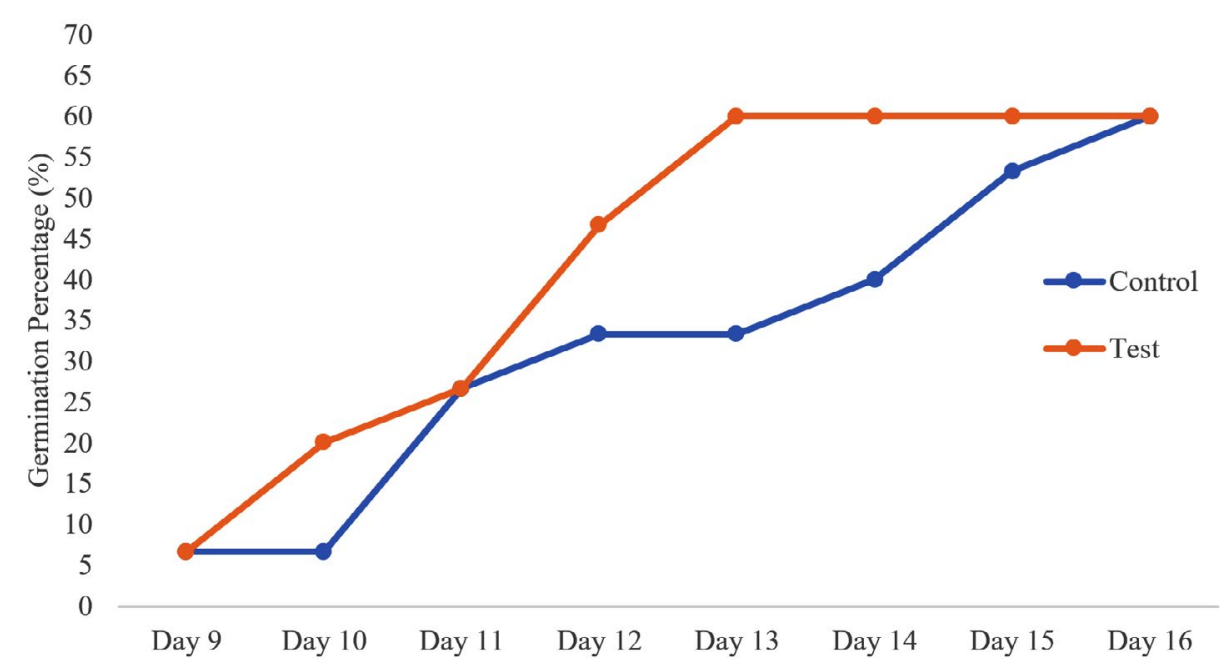

Fig. 6. Germination percentage of chili seeds from day 9 to day 16 . 


\section{Plant Study}

Nine pots were prepared and equally divided into three sets as positive control (PC), negative control (NC) and test. All pots were filled with respective soil until three fourth full. To each pot, 5 chilli seeds were sowed and were watered in the morning. Shoot length, root length and wet weight of plant were measured on $20^{\text {th }}$ day, $25^{\text {th }}$ day and $110^{\text {th }}$ day.

\section{Statistical Analysis}

In this study, data were collected thrice and are reported as mean \pm standard deviation.

\section{RESULTS}

\section{Characterization of Polysaccharides UV-Vis Spectroscopic Analysis}

Absorbance values were obtained at wavelength ranges from 200 to $800 \mathrm{~nm}$, with a peak formed at $254 \mathrm{~nm}$ for crude polysaccharides. For purified polysaccharide, high absorbance was found between $200 \mathrm{~nm}$ and $300 \mathrm{~nm}$ (Fig. 2). In UV-Vis analysis, a peak formed around $254 \mathrm{~nm}$ (crude polysaccharide) might indicate the presence of xylose Oliver et al. ${ }^{18}$ observed the maximum absorbance of xylose at $245 \mathrm{~nm}$ to 255 $\mathrm{nm}$. However, peak at $210 \mathrm{~nm}$ was not observed, which is another wavelength of maximum absorbance for xylose. Purified polysaccharide (Fig. 2 B) showed high absorbance between 200 $\mathrm{nm}$ to $300 \mathrm{~nm}$ might indicate presence of xylose and glucose. ${ }^{18}$

\section{Fourier-Transform Infrared Spectroscopy (FTIR) Analysis}

Fig. 3 shows the spectrum obtained for purified polysaccharide. It showed the formation of band at about $2350 \mathrm{~cm}^{-1}, 2900 \mathrm{~cm}^{-1}$, and also one band in the range between $1200 \mathrm{~cm}^{-1}$ and $1100 \mathrm{~cm}^{-1}$. In FTIR spectrum, the band at around $2900 \mathrm{~cm}^{-1}$ represents the asymmetric $\mathrm{CH}$ stretch of the methylene group and the band at wavenumbers in the range between 1200 and $1100 \mathrm{~cm}^{-1}$ can be attributed to $\mathrm{C}-\mathrm{O}$ stretching of alcohol group or $\mathrm{C}-\mathrm{O}$ stretching vibrations in $\mathrm{C}-\mathrm{O}-\mathrm{C}$ glycosidic linkages of oligosaccharides. ${ }^{19}$ There was one band observed at about $2350 \mathrm{~cm}^{-1}$, which can be assigned to $\mathrm{NH}$ component. ${ }^{20}$

\section{Gas Chromatography (GC) Analysis}

$G C$ analysis confirms the presence of xylose and D-allose (RT at 12.810 and 16 respectively). Samrot et al. ${ }^{11}$ reported these

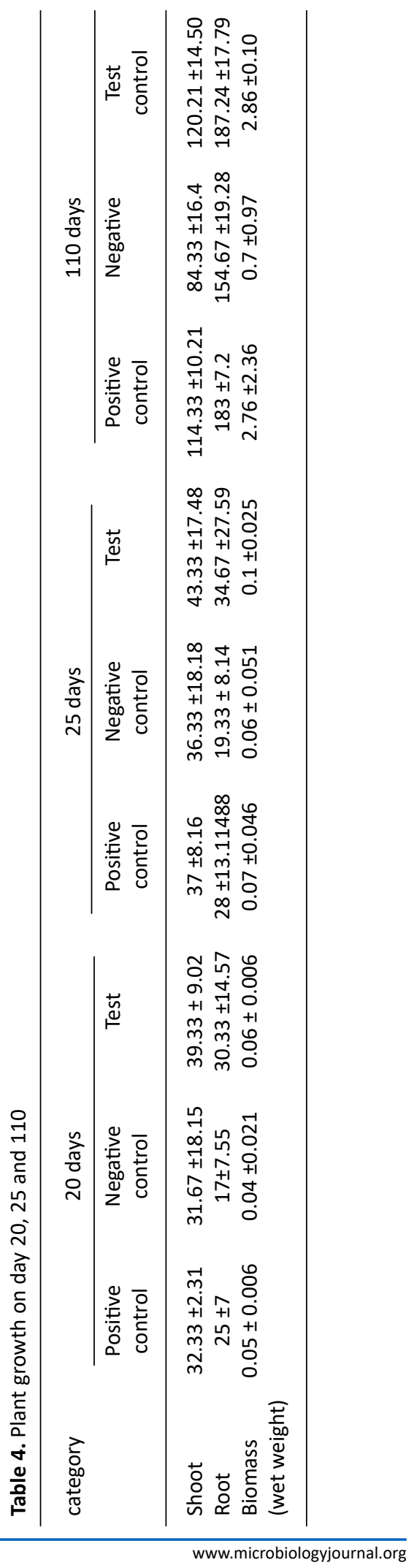


monosaccharides in A. indica gum too. Araucaria heterophylla has been reported to have galactose and xylose. The peaks of various sugar moieties have been determined using GC-MS analysis. ${ }^{21-23}$ Bioactivities of Polysaccharides

\section{Antibacterial Activity}

The absence of zone of inhibition signified the inability of both crude and purified polysaccharide in inhibiting four organisms used in this study (Table 1). This study demonstrated that polysaccharides extracted from MI have no antibacterial activity, probably due to the lack of bioactive compounds whereas leaves of MI has been reported to have antibacterial activity. ${ }^{24}$ As according to a study by Yahia et al. ${ }^{25}$ they showed that the leaves extract of Ziziphus lotus and Ziziphus mauritiana L. possess high antimicrobial activity mainly due to their rich contents of bioactive compounds such as polyphenols, flavonoids and tannins. In contrast to the results obtained in this study, gum of several plant species were demonstrated to exhibit antibacterial activity. Polysaccharide extracted from Azadirachta indica gum can inhibit the growth of $E$. coli at a concentration of $20 \mu \mathrm{g} / \mathrm{ml} .{ }^{11}$ In a study by Samrot et al. ${ }^{26}$ antibacterial activity against Bacillus sp. was found in purified polysaccharide of Araucaria heterophylla L. and Prosopis chilensis L., with their minimal inhibitory concentration reported as $8 \mathrm{mg}$. Also, in another study performed using Ficus iyrata plant gum, there were absence of zone of inhibitions for all the tested organisms (S. aureus, Bacillus sp, E. coli and Klebsiella sp.) tested with water extract and purified polysaccharide. However, chloroform extract showed antibacterial activity against Bacillus sp. at concentration of $4 \mathrm{mg} / \mathrm{ml}, 6 \mathrm{mg} / \mathrm{ml}$ and $8 \mathrm{mg} / \mathrm{ml}^{27}$

\section{Swarming Motility Assay}

Diameter of biofilm obtained for crude polysaccharide was the same as the control for both organisms. In contrast, the diameter of biofilm measured for purified polysaccharide was lower than control for both organisms (Table 2), which indicated better inhibition of swarming motility of microorganisms. ${ }^{28}$ Compared with other studies using different types of plant gum, purified polysaccharide of Terminalia catappa L. gum was found to inhibit swarming motility of Pseudomonas aeruginosa. ${ }^{29}$
In another study, Samrot et $\mathrm{a}^{26}$ found that purified polysaccharide of $A$. heterophylla and $P$. chilensis was able to inhibit swarming motility of Bacillus sp. Antioxidant Activity

DPPH scavenging activity increases with the increase in concentration of both crude and purified polysaccharides. The antioxidant activity of ascorbic acid was notably higher than polysaccharides. Higher scavenging activity was observed in crude polysaccharide when compared to purified polysaccharide (Fig. 5). However, the scavenging effect of crude polysaccharide was not significant because of the huge difference in percentage scavenging compared to ascorbic acid (standard). Similar results were obtained by Samrot et al. ${ }^{11}$ who tested on Azadirachta indica gum, in which the extracted polysaccharide had scavenging activity significantly lower than the control. In contrast to the findings of this study, purified polysaccharide of Terminalia catappa L., A. heterophylla and P. chilensis showed significant antioxidant property as their percentage scavenging was comparable to the standard. ${ }^{26,29}$ Moreover, Samrot et al. ${ }^{27}$ found that water extract of Ficus iyrata gum exhibit significant free radical scavenging effect.

\section{Seed Germination and Seedlings Growth Study Germination Percentage}

Control and test group had $60 \%$ of germination (No more germinated seeds observed after day 16). However, test group reached to this percentage at day 13, 3 days before the control group. Germination did not occur earlier in the test group as both had their first germinated seeds observed on Day 9. Germination Percentage was a higher in the test group, with exception seen on day 9 and 11 (Fig. 6). Gum-treated seeds also showed increased pattern of all parameters i.e. shoot length, root length and wet weight of seedlings. As sugars are an important factor in plant growth and development, the presence of polysaccharides in plant gum makes it a possible growth promoter. According to Ciereszko ${ }^{30}$, germination and other plant development stages are affected by changes in sugars concentration. Hernandez-Herrera et al. ${ }^{7}$ carried out a study on seed germination and seedling growth using extract of brown seaweed Ulva lactuca and Padina gymnospora which contain polysaccharides. Both extracts prepared in 
alkaline conditions slightly enhanced germination of tomato seeds, but showed adverse effect when used in high concentration $(10 \mathrm{mg} / \mathrm{ml})$.

\section{Seedlings Growth}

Fig. 7a-c showed that test groups have mean shoot length, root length and wet weight greater than the controls in every observation day. It was noticed that all the parameters showed an increase trend over the three observations days. Polysaccharide of microalgae has been reported to improve the growth ofSolanum lycopersium and Capsicum annum. ${ }^{31}$ Polysaccharides of Chlorella vulgaris was reported to enhance the seedling growth and also found to increase the protein and carbohydrate content. ${ }^{32}$

Soil Testing

Positive control soil had the largest porosity, with a value of $47.5 \%$. For negative control, soil porosity was determined to be $22 \%$, slightly lower than the test soil i.e. $27 \%$, (Table 3). WHC was found to be $98 \%$ for positive control soil, which is the highest among the three types of soil. Test soil $(70 \%)$ has field capacity higher than the negative control soil (32\%) (Table 3).
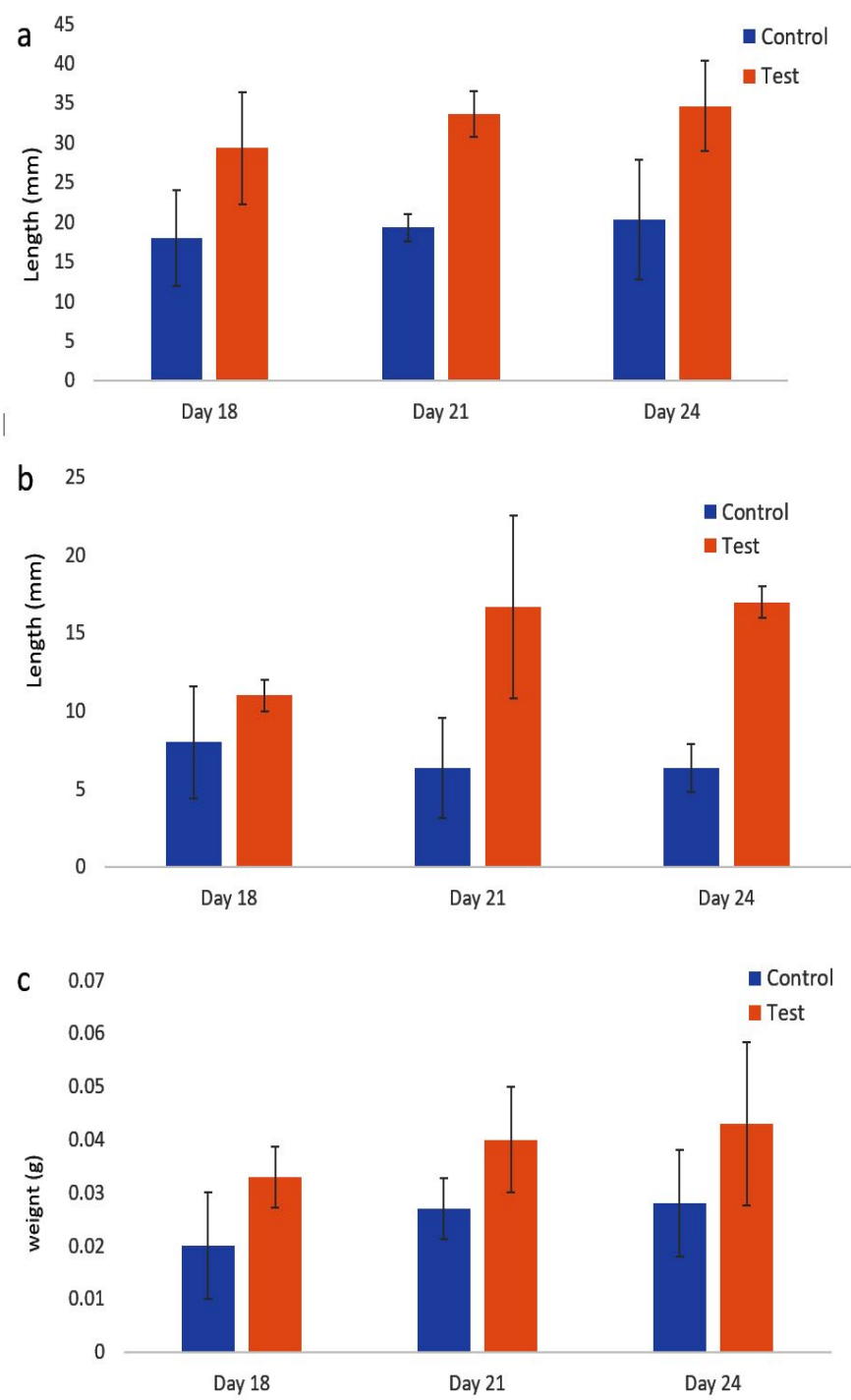

Fig. 7. Parameters measured on day 18, 21 and 24; a-shoot length, b- root length; c- wet weight. 
Results obtained in this study showed increased soil porosity and WHC after addition of plant gum. Soil porosity directly affects WHC, as an increased in soil porosity will lead to enhanced WHC. The results obtained are in consonance with Vengadaramana and Jashothan ${ }^{33}$, who reported significantly increase in WHC of soil treated with cow dung and compost organic fertilizer when compared to the untreated soil. As plants can only absorb nutrients in soluble form, soil with larger WHC supports plant growth better because of its ability to retain more nutrients. ${ }^{34}$ Available water holding capacity (AWHC), which is the amount of water in soil that is available to plants, is a more precise determinator than WHC alone. ${ }^{35}$ Minasny and McBratne. ${ }^{35}$ demonstrated that AWHC only increased by $1.16 \%$ averagely with a $1 \%$ increase in soil organic carbon. ${ }^{29}$ Similarly, Libohova et al. ${ }^{36}$ showed $1 \%$ increase in AWHC.

\section{Plant Study}

The Mean shoot and root length of test group was the highest (greater than positive control) for day 20, 25 and 110 (result not shown here). The increased growth parameters could be contributed by the high polysaccharides content of $\mathrm{Ml} \mathrm{gum}$, in the presence of proteins and lipids. ${ }^{37}$ Biopolymers are found in all forms of manure, including cow and poultry manures, which are well-known for its fertilizing properties. ${ }^{38}$ Naishima et al. ${ }^{16}$ demonstrated the plant to grow larger than control with greater height and stem diameter. Another factor contributes and supported better plant growth is the nutritional supply. MI gum was proven for its nutritional contents of nitrogen, phosphorus, potassium, calcium and iron ${ }^{10}$. All are nutrients required in large quantities for plant to grow and develop, with iron as the only micronutrient. ${ }^{39}$

\section{CONCLUSION}

In conclusion, polysaccharide was extracted from MI gum and purified. Crude and purified polysaccharides were characterized using UV-Vis, FTIR and GC. Both forms of polysaccharide showed weak antioxidant activity and neither of them exhibit antibacterial property. MI gum was found to enhance seed germination, seedling growth and vegetative growth. In this study, addition of $\mathrm{Ml}$ gum to soil increased its porosity and WHC.

\section{ACKNOWLEDGMENTS}

None.

\section{CONFLICT OF INTEREST}

The authors declare that there is no conflict of interest.

\section{AUTHORS' CONTRIBUTION}

All authors designed the experiments. AVS and LSJ performed the experiments. AS, ERR, $D S, P P, S S, S N$, analyzed and helped in writing the paper. All the authors read and approved the work.

\section{FUNDING}

None.

\section{DATA AVAILABILITY}

All datasets generated or analyzed during this study are included in the manuscript

\section{ETHICS STATEMENT}

This article does not contain any studies with human participants or animals performed by any of the authors.

\section{REFERENCES}

1. Mohammadinejad R, Kumar A, Ranjbar-Mohammadi $M$, et al. Recent Advances in Natural Gum-Based Biomaterials for Tissue Engineering and Regenerative Medicine: A Review. Polymers. 2020;12(1):176. doi: 10.3390/polym12010176

2. Hamdani AM, Wani IA, Gani A, Bhat NA, Masoodi FA. Effect of gamma irradiation on physicochemical, structural and rheological properties of plant exudate gums. Innov Food SciEmerg Technol. 2017;44:74-82. doi: 10.1016/j.ifset.2017.07.014

3. Lankalapalli S, Sandhala D. A Review on Natural Gums and Their Uses as Pharmaceutical Excipients. Int J Pharma Sci Res. 2019;10(12):5274-5283.

4. Iravani S. Plant gums for sustainable and eco-friendly synthesis of nanoparticles: recent advances. Inorganic and Nano-metal Chemistry. 2020;50(6):469-488. doi: 10.1080/24701556.2020.1719155

5. Gonzalez A, Castro J, Vera J, Moenne A. Seaweed oligosaccharides stimulate plant growth by enhancing carbon and nitrogen assimilation, basal metabolism, and cell division. Journal of Plant Growth Regulation.2013;32(2):443-448. doi: 10.1007/s00344012-9309-1 
6. Gonzalez A, Contreras RA, Moenne A. Oligocarrageenans enhance growth and contents of cellulose, essential oils and polyphenolic compounds in Eucalyptus globulus trees. Molecules. 2013;18(8):87408751. doi: $10.3390 /$ molecules 18088740

7. Hernandez-Herrera RM, Santacruz-Ruvalcaba F, Zanudo-Hernandez J, Hernandez-Carmona G. Activity of seaweed extracts and polysaccharide-enriched extracts from Ulva lactuca and Padina gymnospora as growth promoters of tomato and mung bean plants. J Appl Phycol. 2016;28(4):2549-2560. doi: 10.1007/ s10811-015-0781-4

8. Burns RG, DeForest JL, Marxsen J, et al. Soil enzymes in a changing environment: Current knowledge and future directions. Soil Biology and Biochemistry. 2013;58:216-234. doi: 10.1016/j.soilbio.2012.11.009

9. Govindan V. Mango (Mangifera indica L.), plant produces an exotic fruits on stem. Int J Innov Res Sci Eng Technol. 2019;9(4):8-13.

10. Azanu D, Oppong A, Darko C, Bondzie S, Owusu-Ansah G. Physico-Chemical Properties of Some Selected Plant Gum Exudates in Ghana. EC Pharmacological and Toxicology. 2019;7(3):152-160.

11. Samrot AV, Angalene JLA, Roshini SM, et al. Purification, characterization and exploitation of Azadirachta indica gum for the production of drug loaded nanocarrier. Materials Research Express. 2020a;7(5):1-14. doi: 10.1088/2053-1591/ab8b16

12. Sangeethpriya ES, Raji P, Saranya CR, Shilpa T, Samrot AV. Phytochemical Screening and Bioactivity of Some Indian Medicinal Plants. J Pure Appl Microbiol. 2014;8(6):4859-4865

13. Balouiri M, Sadiki M, Ibnsouda SK. Methods for in vitro evaluating antimicrobial activity: A review. Journal of Pharmaceutical Analysis. 2016;6(2):71-79. doi: 10.1016/j.jpha.2015.11.005

14. Samrot AV, Raji P, Selvarani AJ, et al. A Handbook on phytochemical extraction, screening and its in-vitro bioactivity assays. Nagercoil: SARAS Publisher; 2020c.

15. Raji P, Abila MG, Renugadevi K, Samrot AV. Phytochemical screening and bioactivity studies of Cassia fistula leaves. International Journal of ChemTech Research. 2014;6(12):5096-5100.

16. Naishima ASI, Kalu PM, Igba AJ. Assessment of Seed Germination and Organic Manure Application on the Early Growth of Eucalyptus camaldulensis L. Seedlings. Research Journal of Forestry. 2019;13(1):1-8. doi: 10.3923/rjf.2019.1.8

17. Omar L, Ahmed OH, Ab Majid NM. Improving Ammonium and Nitrate Release from Urea Using Clinoptilolite Zeolite and Compost Produced from Agricultural Wastes. The Scientific World Journal. 2015;2015:574201. doi: 10.1155/2015/574201

18. Oliver JD, Gaborieau M, Hilder EF, Castignolles P. Simple and robust determination of monosaccharides in plant fibers in complex mixtures by capillary electrophoresis and high performance liquid chromatography. Journal of Chromatography A. 2013;1291:179-186. doi: 10.1016/j.chroma.2013.03.041

19. Coates J. Interpretation of Infrared Spectra, A Practical Approach. Encyclopedia of Analytical Chemistry. 2000;12:10815-10837.
20. Nandiyanto ABD, Oktiana R, Ragadhita R, Sukmafitri A, Zaen R. Amorphous content on the photocatalytic performance of micrometer-sized tungsten trioxide particles. Arabian Journal of Chemistry. 2020;13(1):2912-2924. doi: 10.1016/j. arabjc.2018.07.021

21. Anderson DMW, Munro AC. An analytical study of gum exudates from the genus Araucaria jussieu (gymnospermae). Carbohydr Res. 1969;11:43-51. doi: 10.1016/S0008-6215(00)80640-0

22. Poinsot V, Carpene MA, Couderc F. Coupled mass spectrometric strategies for the determination of carbohydrates at very low concentrations: the case of polysaccharides involved in the molecular dialogue between plants and rhizobia. Complex World Polysaccharides; 2012.

23. Ye F, Yan X, Xu J, Chen H. Determination of Aldoses and Ketoses by GC-MS using Differential derivatisation. Phytochem Anal.2006;17(6):379-383. doi: 10.1002/ pca.928

24. Samrot AV, Rohan BD, Kumar D, Sahiti K, Raji $P$, Samanvitha SK. Detection of antioxidant and antibacterial activity of Mangifera indica using TLC bio-autography. Int J Pharma Sci Res. 2016;7(11):44674472. doi: 10.13040/IJPSR.0975-8232.7(11).4467-72

25. Yahia Y, Benabderrahim MA, Tlili N, Bagues M, Nagaz K. Bioactive compounds, antioxidant and antimicrobial activities of extracts from different plant parts of two Ziziphus Mill. species. PLOS ONE. 2020;15(5):e0232599. doi: 10.1371/journal.pone.0232599

26. Samrot AV, Kudaiyappan T, Bisyarah U., et al. Extraction, Purification, and Characterization of Polysaccharides of Araucaria heterophylla $L$ and Prosopis chilensis $L$ and Utilization of Polysaccharides in Nanocarrier Synthesis. Int J Nanomedicine. 2020b;15:7097-7115. doi: 10.2147/IJN.S259653

27. Samrot AV, Bisyarah U, Kudaiyappan T, Etel F, Abubakar A. Ficus iyrata plant gum derived polysaccharide based nanoparticles and its application. Biocatalysis and Agricultural Biotechnology. 2021;31(2):101871. doi: 10.1016/j.bcab.2020.101871

28. Nashikkar N, Begde D, Bundale S, Pise M, Rudra J, Upadhyay A. Inhibition of Swarming Motility, Biofilm Formation and Virulence Factor Expression of Urinary Pathogens by Euphorbia trigona Latex Extracts. Int $J$ Pharma Sci Res. 2011;2(3):558-566.

29. Samrot AV, Suvedhaa B, Sahithya CS, Madankumar A. Purification and Utilization of Gum from Terminalia Catappa L. for Synthesis of Curcumin Loaded Nanoparticle and Its In Vitro Bioactivity Studies. Journal of Cluster Science. 2018;29(9):989-1002. doi: 10.1007/s10876-018-1412-4

30. Ciereszko I. Regulatory roles of sugars in plant growth and development. Acta Societatis Botanicorum Poloniae. 2018;87(2):3583. doi: 10.5586/asbp.3583

31. Elarroussi H, Elmerissi N, Benhima R, et al. Microalgae polysaccharides a promising plant growth biostimulant. J Algal Biomass UtIn. 2016;7(4):55-63.

32. El-Naggar NA, Hussein MH, Shaaban-Dessuuki SA, Dalal SR. Production, extraction and characterization of Chlorella vulgaris soluble polysaccharides and their applications in AgNPs biosynthesis and biostimulation 
of plant growth. Sci Rep. 2020;10(1):3011. doi: 10.1038/s41598-020-59945-w

33. Vengadaramana A, Jashothan PTJ. Effect of Organic Fertilizer on the Water Holding Capacity of Soil in Different Terrains of Jaffna Peninsula in Sri Lanka. Journal of Natural Product and Plant Resources. 2012;2(4):500-503.

34. Kizito S, Luo HZ, Lu JX, Bah H, Dong RJ, Wu SB. Role of Nutrient-Enriched Biochar as a Soil Amendment during Maize Growth: Exploring Practical Alternatives to Recycle Agricultural Residuals and to Reduce Chemical Fertilizer Demand. Sustainability. 2019;11(11):3211. doi: 10.3390/su11113211

35. Minasny B, McBratney AB. Limited effect of organic matter on soil available water capacity. European Journal of Soil Science. 2017;69(1):39-47. doi: 10.1111/ ejss. 12475

36. Libohova Z, Seybold C, Wysocki D, et al. Reevaluating the effects of soil organic matter and other properties on available water-holding capacity using the National Cooperative Soil Survey Characterization Database. Journal of Soil and Water Conservation. 2018;73(4):411-421. doi: 10.2489/jswc.73.4.411

37. Amid BT, Mirhosseini H. Effect of different purification techniques on the characteristics of heteropolysaccharide-protein biopolymer from durian (Durio zibethinus) seed. Molecules. 2012;17(9):1087510892. doi: $10.3390 /$ molecules 170910875

38. Park JK, Cho KH, Ligaray M, Choi MJ. Organic Matter Composition of Manure and Its Potential Impact on Plant Growth. Sustainability. 2019;11(8):2346. doi: 10.3390/su11082346

39. Bahamonde HA, Fernandez V, Gyenge J, Mattenet F, Peri PL. Essential Nutrient and Trace Element Foliar Resorption of Two Co-Existing Nothofagus Species Grown Under Different Environmental Conditions in Southern Patagonia. Frontiers in Plant Science. 2019;10:1542. doi: 10.3389/fpls.2019.01542 